\title{
JAOS
}

\section{Cephalometric changes during aging in subjects with normal occlusion}

\section{Abstract}

Daniela GARIB ${ }^{1}$

Gabriela Manami NATSUMEDA ${ }^{1 *}$

Camila MASSARO ${ }^{1}$

Felicia MIRANDA ${ }^{1}$

Rodrigo NAVEDA ${ }^{1}$

Guilherme JANSON ${ }^{1}$ iD
Submitted: April 4, 2021 Modification: July 1, 2021

Accepted: August 4, 2021
Objective: To assess craniofacial changes from early adulthood to the seventh decade of life in individuals with normal occlusion. Methodology: The sample comprised lateral cephalograms of 21 subjects with normal occlusion (11 male, 10 female), taken at 17 (T1) and 61 years of age (T2). Anteroposterior and vertical maxillomandibular relationships, and dentoalveolar and soft tissue changes were analyzed. Interphase comparisons were performed using paired t-tests. Differences between sexes, and subgroups with and without tooth loss were evaluated using t-tests $(p<0.05)$. Results: Maxillary and mandibular anterior displacement, and facial and ramus height increased from T1 to T2. Maxillary molars showed significant mesial angulation. Maxillary and mandibular molars, and mandibular incisors developed vertically during the evaluation period. Soft tissue changes included a decrease of the nasolabial angle, upper and lower lip retrusion, decrease of upper lip thickness and increase of the lower lip and soft chin thickness. Maxillary incisor exposure by the upper lip decreased $3.6 \mathrm{~mm}$ in 40 years. Males presented counterclockwise rotation of the mandible, whereas females showed mandibular clockwise rotation and backward displacement of the chin. The group with tooth loss showed a greater increase of the posterior facial height and ramus height. Conclusion: We observed aging changes in dentoskeletal structures and soft tissue, as well as sexual differences for craniofacial changes during the maturational process. Subjects with multiple tooth losses showed a greater increase in mandibular ramus height.

Keywords: Age factors. Balanced dental occlusion. Aging. Cephalometry.

'Universidade de São Paulo, Faculdade de Odontologia de Bauru, Departamento de Odontopediatria, Ortodontia e Saúde Coletiva, Bauru, SP, Brasil.

*This article is based on research submitted by Dr. Gabriela Manami Natsumeda in partial fulfillment of the requirements of the degree of M.Sc. in Orthodontics at Bauru Dental School, University of São Paulo, Bauru-SP, Brazil. 


\section{Introduction}

Life expectancy remarkably increased in the last century. Craniofacial growth and development are continuous processes, and maturational changes can occur during aging. ${ }^{1,2}$ The number of adults who seek orthodontic treatment for functional or esthetic improvement has increased, and understanding the natural changes that occur throughout life in the craniofacial complex is extremely important. Most previous longitudinal studies evaluated changes in the first two decades of life. ${ }^{3-6}$ Previous studies show that growth continues during adulthood, , ${ }^{1,2,-15}$ rather than immediately stopping after puberty. ${ }^{14}$

Behrents $^{1}$ (1984) showed that craniofacial growth is a continuous process during human aging. In his detailed study in a nontreated sample from 25 to 83 years of age, men showed forward and downward mandibular displacement, whereas women showed backward mandibular rotation. The soft pogonion became more prominent, especially in men. ${ }^{1}$ The soft tissue glabella continued to move forward, with retrusion of the upper lip. ${ }^{1}$ The author reported only mild changes between 40 and 80 years of age. ${ }^{1}$ A study by Formby, et al. ${ }^{10}$ (1994) demonstrated that facial profiles straightened with age only in men. A previous maturational study until the fifth decade of life showed that men presented anterior rotation of the mandible, whereas women showed posterior mandibular rotation. ${ }^{15}$ A study with untreated subjects from 17 to 57 years of age reported that changes in the soft tissue were more evident than dentoskeletal changes with aging, including a flattening and elongation of the upper lip, and drooping of the nasal tip and columella. ${ }^{14}$ Only one previous cephalometric study evaluated aging in normal occlusion subjects, showing that facial anteroposterior and vertical dimensions increased from 25 to 46 years of age. ${ }^{2}$

Previous cephalometric studies on craniofacial maturational changes have evaluated untreated samples until the fifth decade of life. ${ }^{10,14,15}$ No previous study has evaluated cephalometric maturational changes in a sample of individuals with normal occlusion with a 40-year follow-up period. Therefore, our study aimed to evaluate the dentoskeletal and soft tissue changes in individuals with normal occlusion from 17 to 61 years of age and the influence of sex and permanent tooth losses on craniofacial changes.

\section{Methodology}

This observational and longitudinal study was approved by the Ethics in Research Committee of Bauru Dental School, University of São Paulo, protocol \#71634917.5.0000.5417. Lateral cephalograms of white Brazilians taken at an initial mean age of 17.61 years ( $S D=0.96$, range: 16.1 to 19.6 ) were used (T1). All subjects had balanced facial profiles with no excessive protrusion or retrusion and clinically acceptable occlusion in the complete permanent dentition, with dental Class I relationships, normal overjet and overbite, absence of crossbites, maximum $2 \mathrm{~mm}$ of incisor crowding, and no previous orthodontic treatment. From 2015 to 2016 (T2), the sample was recalled and lateral cephalograms were obtained for this study at a mean age of 61.34 years ( $S D=1.57$, range: 58.6 to 63.6 ). The exclusion criteria for T2 records were history of orthodontic treatment between $\mathrm{T} 1$ and $\mathrm{T} 2$, and complete loss of the posterior teeth in one or both dental arches. The final sample consisted of 21 subjects, 11 males with initial age of 17.90 years $(S D=0.91)$ and final age of $61.52(S D=1.59)$, and 10 females with initial age of 17.29 years $(S D=0.91)$ and final age of 61.13 years $(S D=1.61)$. The enrollment process is shown in Figure 1. In our sample, up to one tooth loss without prosthetic rehabilitation was observed in nine out of 21 subjects, who were placed in the subgroup without tooth losses. Two or more tooth losses without prosthetic rehabilitation were observed in the other 12 individuals, who were placed in the subgroup with tooth losses. Active periodontal disease was not observed in on clinical examination, considered as bleeding on probing. ${ }^{17}$

All T1 cephalograms were scanned and all cephalograms were analyzed with the Dolphin Imaging ${ }^{\circledR} 11.5$ software (Dolphin Imaging, Chatsworth, Calif., USA). Correction of $11 \%$ and $10 \%$ magnification factors for T1 and T2 were performed, respectively. In total, 39 cephalometric variables were evaluated (Table 1). Variables were grouped in Table 1 according to cranial base, maxillary and mandibular skeletal component, maxillomandibular relationship, vertical component, maxillary and mandibular dentoalveolar component, dental relationship, and soft tissue. ${ }^{14,15}$ 


\section{Statistical analyses}

Mean and standard deviation were estimated for all measurements at T1 and T2. Kolmogorov-Smirnov tests showed normal distribution for all variables. Interphase changes from $\mathrm{T} 1$ to $\mathrm{T} 2$ were evaluated using paired $t$-tests. Differences between males and females, and between subgroups with and without tooth losses were also investigated with $t$-tests. A $5 \%$ significance level was considered. HolmBonferroni correction for multiple comparisons was applied. ${ }^{19}$ For the error study, $50 \%$ of the sample was randomly remeasured by the same examiner (G.M.N) after a minimum 30-day interval. Random errors were estimated using Dahlberg's formula ${ }^{18}$, and systematic errors were estimated with dependent $t$-tests, at a $5 \%$ significance level. Statistical analyses were performed using the Statistica ${ }^{\odot}$ software (Statistica for Windows, StatSoft Inc., Tulsa, USA). A post-hoc power analysis was also evaluated using the bilateral parametric test from the GPower software (Version 3.1.9.7, Heinrich-Heine-University, Düsseldorf, Germany).

\section{Results}

Random errors ranged from $0.21 \mathrm{~mm}$ to $1.82 \mathrm{~mm}$ for linear variables (overjet and Co-Go, respectively), and from $0.32^{\circ}$ to $1.61^{\circ}$ for the angular measurements (SNB and Mx1.Md1, respectively). We found no significant systematic error. The achieved power was 0.99 , considering a mean change of $6 \mathrm{~mm}$ in the CoGn

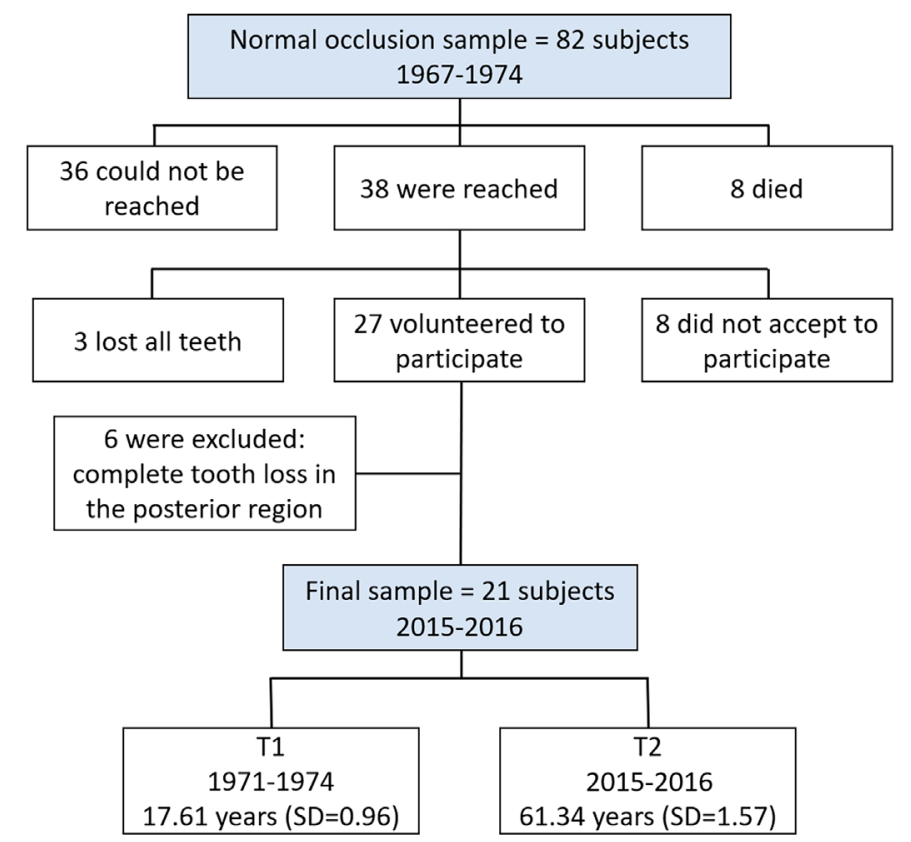

Figure 1- The enrollment process and age distribution during the 40-year follow-up
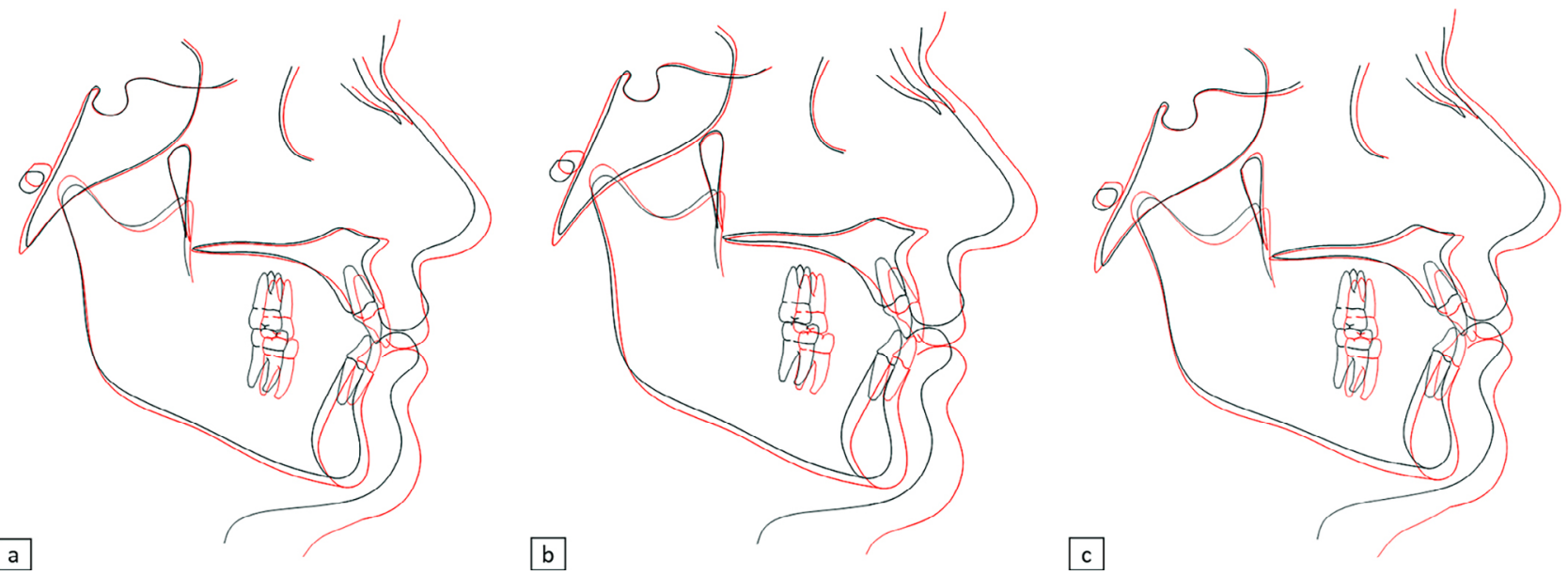

Figure 2- Facial and regional tracing superimposed in the cranial base, centered at S (T1-black; T2-red). a-Average of complete sample. b - Average of male subjects; $c$ - Average of female subjects 
variable and a 5\% significance level.

\section{Interphase changes}

From 17 to 61 years of age, we observed a significant increase of $2.74 \mathrm{~mm}(p<0.001)$ in the anterior cranial base. The maxillary and mandibular lengths increased $5.40 \mathrm{~mm}$ and $6.60 \mathrm{~mm}(p<0.001)$, respectively. We also observed maxillary and mandibular anterior displacements of $1.47 \mathrm{~mm}$ $(p<0.001)$ and $2.42 \mathrm{~mm}(p<0.001)$, respectively (Figure 2a, Table 2). The measurements showed a significant increase of the upper and lower facial height $(0.74 \mathrm{~mm}$ and $2.44 \mathrm{~mm}$, respectively), of the posterior facial height $(3.38 \mathrm{~mm})$, and of the ramus height $(5.36 \mathrm{~mm})$. Maxillary molars showed a significant mesial angulation of $3.50^{\circ}(p<0.001)$, and a vertical development of $2.74 \mathrm{~mm}(p<0.001)$. Mandibular incisors and molars also showed a

Table 1- Skeletal, dental, soft tissue profile cephalometric variables

\begin{tabular}{|c|c|}
\hline Variables & Definition \\
\hline \multicolumn{2}{|r|}{ Cranial Base } \\
\hline S-N (mm) & Distance between $\mathrm{S}$ and $\mathrm{N}$ points \\
\hline \multicolumn{2}{|r|}{ Maxillary Skeletal Component } \\
\hline $\operatorname{SNA}\left({ }^{\circ}\right)$ & $\mathrm{SN}$ to NA angle \\
\hline $\mathrm{CoA}(\mathrm{mm})$ & Condylion to A-point distance \\
\hline A-NPerp (mm) & A point to nasion-perpendicular \\
\hline \multicolumn{2}{|r|}{ Mandibular Skeletal Component } \\
\hline SNB $\left({ }^{\circ}\right)$ & SN to NB angle \\
\hline Co-Gn (mm) & Condylion to Gnathion distance \\
\hline P-Nperp (mm) & Point $P$ relative to the perpendicular passing through $N$ \\
\hline \multicolumn{2}{|r|}{ Maxillomandibular relatioship } \\
\hline ANB $\left({ }^{\circ}\right)$ & NA to NB angle \\
\hline $\mathrm{mx} / \mathrm{md} \operatorname{dif}(\mathrm{mm})$ & Difference between mandibular and maxillary length \\
\hline \multicolumn{2}{|r|}{ Vertical Component } \\
\hline OP.FH $\left({ }^{\circ}\right)$ & Oclusal plane to Frankfurt plane angle \\
\hline PP.FH $\left({ }^{\circ}\right)$ & Palatal plane to Frankfurt plane angle \\
\hline FMA $\left({ }^{\circ}\right)$ & Frankfurt mandibular plane \\
\hline SNGoGn $\left({ }^{\circ}\right)$ & SN to GoGn angle \\
\hline UFH (mm) & Distance between $\mathrm{N}$ and ANS points \\
\hline LAFH (mm) & Distance bewteen ANS and Me points \\
\hline $\mathrm{PFH}(\mathrm{mm})$ & Distance between $\mathrm{S}$ and Go points \\
\hline Co-Go $(\mathrm{mm})$ & Condylion to gonion distance \\
\hline \multicolumn{2}{|r|}{ Maxillary dentoalveolar component } \\
\hline Mx1.NA $\left({ }^{\circ}\right)$ & Maxillary incisor long axis to $\mathrm{Na}$ angle \\
\hline $\mathrm{M} \times 1-\mathrm{NA}(\mathrm{mm})$ & Distance between anterior point of crown of maxillary incisor and NA line \\
\hline $\mathrm{Mx} 1-\mathrm{PP}(\mathrm{mm})$ & Distance between maxillary incisal edge and palatal plane \\
\hline Mx6.SN $\left({ }^{\circ}\right)$ & Angle formed by the long axis of maxillary first molar and SN plane \\
\hline Mx6-PP (mm) & Mean perpendicular distance between mesial and distal cusps of maxillary first molar and palatal plane \\
\hline \multicolumn{2}{|r|}{ Mandibular dentoalveolar component } \\
\hline $\operatorname{Md1.NB}\left({ }^{\circ}\right)$ & Mandibular incisor long axis to NB angle \\
\hline Md1-NB (mm) & Distance between the most anterior point of crown of mandibular incisor and NB line \\
\hline $\operatorname{IMPA}\left({ }^{\circ}\right)$ & Incisor mandibular plane angle \\
\hline Md1-MP (mm) & Distance between mandibular incisal edge and mandibular plane \\
\hline Md6.MP $\left({ }^{\circ}\right)$ & Angle formed by the long axis of mandibular first molar and MP \\
\hline Md6-MP (mm) & Distance between occlusal point of mandibular first molar and mandibular plane \\
\hline \multicolumn{2}{|r|}{ Dental relationship } \\
\hline Overjet (mm) & Distance between the incisal edge of maxillary and mandibular central incisor, parallel to occlusal plane \\
\hline Overbite $(\mathrm{mm})$ & Distance between the incisal edge of maxillary and mandibular central incisor, perpendicular to occlusal plane \\
\hline $\operatorname{Mx1.Md1}\left({ }^{\circ}\right)$ & Angle between the long axis of $\mathrm{Mx} 1$ and $\mathrm{Md} 1$ \\
\hline \multicolumn{2}{|r|}{ Soft Tissue Profile } \\
\hline Nasolabial Angle $\left({ }^{\circ}\right)$ & Angle formed between the nose and upper lip \\
\hline UL cant $\left({ }^{\circ}\right)$ & Upper lip inclination \\
\hline UL-E plane (mm) & Distance between upper lip to E plane \\
\hline LL-E plane (mm) & Distance between lower lip to E plane \\
\hline UL thickness (mm) & Distance between UL to $M \times 1$ \\
\hline LL thickness (mm) & Distance between LL to Md1 \\
\hline Chin thickness (mm) & Distance between Pog to Pog' \\
\hline Mx1 exposure (mm) & Mx1 vertical exposition by the upper lip \\
\hline
\end{tabular}


significant vertical development of $1.20 \mathrm{~mm}$ and 0.91 $\mathrm{mm}$, respectively. The nasolabial angle significantly decreased $\left(6.10^{\circ}\right)$, and we observed a retrusion of the upper (3.5 mm) and lower lips (2.35 mm). Soft tissue thickness significantly decreased in the upper lip ( $2.52 \mathrm{~mm}$; $\mathrm{p}<0.001)$, whereas the lower lip and softtissue chin thickness significantly increased by 1.28 $\mathrm{mm}(\mathrm{p}<0.005)$ and $2.76 \mathrm{~mm}(\mathrm{p}<0.001)$, respectively. Exposure of the maxillary incisor decreased $3.68 \mathrm{~mm}$ $(p<0.001)$ within 40 years.

\section{Sexual differences}

Long-term craniofacial changes presented sexual dimorphism (Figures 2b, c; Table 3). In

Table 2- Interphase comparisons in all 21 subjects (paired t-tests)

\begin{tabular}{|c|c|c|c|c|c|c|c|c|}
\hline \multirow[t]{2}{*}{ Variables } & \multicolumn{2}{|c|}{ T1 } & \multicolumn{2}{|c|}{ T2 } & \multicolumn{2}{|c|}{ T2-T1 } & \multirow[t]{2}{*}{$\mathrm{Cl} 95 \%$} & \multirow[t]{2}{*}{$\mathbf{p}$} \\
\hline & Mean & SD & Mean & SD & Mean & SD & & \\
\hline \multicolumn{9}{|c|}{ Cranial Base } \\
\hline S-N (mm) & 67.34 & 3.99 & 70.08 & 4.05 & 2.74 & 0.99 & -3.19 to -2.29 & $<0.001^{*}$ \\
\hline \multicolumn{9}{|c|}{ Maxillary Skeletal Component } \\
\hline $\operatorname{SNA}\left({ }^{\circ}\right)$ & 82.56 & 3.72 & 82.84 & 3.88 & 0.28 & 1.49 & -0.96 to 0.39 & 0.398 \\
\hline $\mathrm{CoA}(\mathrm{mm})$ & 82.56 & 5.00 & 87.97 & 4.97 & 5.40 & 1.40 & -6.04 to -4.76 & $<0.001^{*}$ \\
\hline A-Nperp (mm) & -0.03 & 2.86 & 1.43 & 2.96 & 1.47 & 1.50 & -2.15 to -0.78 & $<0.001^{*}$ \\
\hline \multicolumn{9}{|c|}{ Mandibular Skeletal Component } \\
\hline SNB $\left({ }^{\circ}\right)$ & 80.16 & 2.96 & 80.24 & 3.46 & 0.08 & 1.54 & -0.78 to 0.62 & 0.812 \\
\hline Co-Gn (mm) & 114.65 & 6.63 & 121.26 & 7.36 & 6.60 & 1.35 & -7.22 to -5.98 & $<0.001^{*}$ \\
\hline P-Nperp (mm) & -2.55 & 3.22 & -0.13 & 4.69 & 2.42 & 4.17 & -4.32 to -0.52 & $0.015^{\star}$ \\
\hline \multicolumn{9}{|c|}{ Maxillomandibular relationship } \\
\hline ANB $\left({ }^{\circ}\right)$ & 2.38 & 1.99 & 2.63 & 2.50 & 0.25 & 1.42 & -0.90 to 0.39 & 0.426 \\
\hline $\mathrm{mx} / \mathrm{md}$ dif. (mm) & 32.16 & 3.54 & 33.28 & 4.07 & 1.12 & 1.73 & -1.91 to -0.33 & 0.007 \\
\hline \multicolumn{9}{|c|}{ Vertical Component } \\
\hline OP.FH $\left({ }^{\circ}\right)$ & 7.34 & 2.37 & 3.83 & 4.58 & -3.50 & 4.81 & 0.94 to 6.06 & 0.010 \\
\hline PP.FH $\left(^{\circ}\right)$ & -0.08 & 2.33 & -1.37 & 3.30 & -1.28 & 2.14 & 0.31 to 2.26 & 0.012 \\
\hline $\mathrm{FMA}\left({ }^{\circ}\right)$ & 24.57 & 2.83 & 22.19 & 4.00 & -2.37 & 3.09 & 0.96 to 3.78 & 0.002 \\
\hline SNGoGn $\left({ }^{\circ}\right)$ & 28.76 & 3.26 & 28.27 & 4.65 & -0.50 & 2.40 & -0.60 to 1.59 & 0.357 \\
\hline UFH (mm) & 50.56 & 2.33 & 51.31 & 2.47 & 0.74 & 0.77 & -1.10 to -0.39 & $<0.001^{*}$ \\
\hline LAFH (mm) & 65.89 & 5.83 & 68.33 & 6.09 & 2.44 & 1.97 & -3.34 to -1.54 & $<0.001^{*}$ \\
\hline $\mathrm{PFH}(\mathrm{mm})$ & 80.76 & 6.26 & 84.15 & 7.22 & 3.38 & 2.21 & -4.39 to -2.37 & $<0.001^{*}$ \\
\hline Co-Go (mm) & 60.20 & 4.73 & 65.56 & 6.14 & 5.36 & 2.79 & -6.63 to -4.90 & $<0.001^{*}$ \\
\hline \multicolumn{9}{|c|}{ Maxillary dentoalveolar component } \\
\hline $\mathrm{Mx} 1 . \mathrm{NA}\left({ }^{\circ}\right)$ & 18.80 & 4.96 & 21.71 & 6.73 & 2.90 & 6.47 & -5.85 to 0.04 & 0.053 \\
\hline $\mathrm{M} \times 1-\mathrm{NA}(\mathrm{mm})$ & 3.43 & 1.64 & 3.35 & 2.66 & -0.07 & 1.88 & -0.77 to 0.93 & 0.190 \\
\hline $\mathrm{Mx1-PP}(\mathrm{mm})$ & 27.85 & 3.05 & 28.59 & 4.06 & 0.73 & 1.66 & -1.49 to 0.01 & 0.055 \\
\hline $\operatorname{Mx6.SN}\left({ }^{\circ}\right)$ & 74.44 & 3.49 & 77.94 & 4.62 & 3.50 & 4.88 & -6.10 to -0.85 & $0.011^{*}$ \\
\hline Mx6-PP (mm) & 19.59 & 2.66 & 22.34 & 3.01 & 2.74 & 1.86 & -3.75 to -1.75 & $<0.001^{*}$ \\
\hline \multicolumn{9}{|c|}{ Mandibular dentoalveolar component } \\
\hline $\operatorname{Md1.NB}\left({ }^{\circ}\right)$ & 23.09 & 4.23 & 24.67 & 5.27 & 1.58 & 4.13 & -3.76 to 0.29 & 0.094 \\
\hline Md1-NB (mm) & 4.19 & 1.62 & 4.57 & 1.78 & 0.37 & 1.02 & -0.84 to 0.08 & 0.105 \\
\hline $\operatorname{IMPA}\left({ }^{\circ}\right)$ & 88.20 & 4.78 & 90.06 & 5.92 & 1.86 & 4.54 & -3.92 to 0.20 & 0.074 \\
\hline Md1-MP (mm) & 38.40 & 3.00 & 39.60 & 3.06 & 1.20 & 1.35 & -1.82 to -0.58 & $<0.001^{*}$ \\
\hline Md6.MP $\left(^{\circ}\right)$ & 82.04 & 4.05 & 80.84 & 7.24 & -1.19 & 8.19 & -2.75 to 5.14 & 0.533 \\
\hline Md6-MP (mm) & 31.61 & 2.94 & 32.52 & 3.45 & 0.91 & 1.44 & -1.60 to -0.21 & $0.034^{*}$ \\
\hline \multicolumn{9}{|c|}{ Dental Relationship } \\
\hline Overjet (mm) & 2.49 & 0.86 & 2.32 & 1.43 & -0.17 & 0.95 & -0.33 to 0.68 & 0.481 \\
\hline Overbite (mm) & 1.90 & 1.21 & 1.76 & 1.20 & -0.13 & 1.26 & -0.53 to 0.81 & 0.665 \\
\hline $\operatorname{Mx1.Md1~}\left({ }^{\circ}\right)$ & 136.52 & 6.89 & 132.89 & 10.88 & -3.63 & 9.27 & -0.58 to 7.85 & 0.087 \\
\hline \multicolumn{9}{|c|}{ Soft tissue } \\
\hline Nasolabial Angle $\left({ }^{\circ}\right)$ & 109.45 & 8.66 & 103.34 & 11.06 & -6.10 & 11.17 & 1.01 to 11.19 & $0.021^{*}$ \\
\hline UL cant $\left(^{\circ}\right)$ & 5.51 & 6.60 & 5.04 & 8.59 & -0.46 & 8.24 & -3.28 to 4.21 & 0.797 \\
\hline UL-Eplane (mm) & -3.90 & 1.85 & -7.40 & 3.30 & -3.50 & 2.37 & 2.41 to 4.58 & $<0.001^{*}$ \\
\hline LL-Eplane (mm) & -2.49 & 1.68 & -4.84 & 2.77 & -2.35 & 1.64 & 1.61 to 3.10 & $<0.001^{*}$ \\
\hline UL thickness (mm) & 13.36 & 1.81 & 10.84 & 1.81 & -2.52 & 1.69 & 1.74 to 3.29 & $<0.001^{*}$ \\
\hline LL thickness (mm) & 11.92 & 1.86 & 13.21 & 2.54 & 1.28 & 1.91 & -2.15 to -0.41 & $0.005^{\star}$ \\
\hline Chin thickness (mm) & 11.66 & 1.62 & 14.42 & 2.37 & 2.76 & 1.86 & -3.61 to -1.91 & $<0.001^{*}$ \\
\hline Mx1 exposure $(\mathrm{mm})$ & 3.10 & 1.25 & -0.57 & 2.05 & -3.68 & 1.95 & 2.79 to 4.57 & $<0.001^{*}$ \\
\hline
\end{tabular}

*Statistically significant after applying Holm-Bonferroni correction ( $p$-values regarded stepwise from 0.002 to 0.05 ). 
males, angular measurements showed slight maxillary and mandibular protrusion $\left(0.89^{\circ}\right.$ and $0.93^{\circ}$, respectively), greater increase of mandibular effective length, counterclockwise rotation of the mandible, and greater increase of the ramus height compared to females (Figure $2 \mathrm{~b}$ ). In females, angular measurements showed slight maxillary retrusion $\left(0.38^{\circ}\right)$, backward displacement of the chin $\left(0.86^{\circ}\right)$ and mandibular clockwise rotation (Figure $2 \mathrm{c}$ ). Additionally, males showed significantly greater retrusion of the upper and lower lips, and greater thickness increase of the soft chin.

Table 3- Male and female change comparisons (t-tests)

\begin{tabular}{|c|c|c|c|c|c|c|}
\hline \multirow[t]{2}{*}{ Variables } & \multicolumn{2}{|c|}{ Male $(n=11)$} & \multicolumn{2}{|c|}{ Female $(n=10)$} & \multirow[t]{2}{*}{ Cl 95\% } & \multirow[t]{2}{*}{$\mathbf{p}$} \\
\hline & Mean & SD & Mean & SD & & \\
\hline \multicolumn{7}{|c|}{ Cranial Base } \\
\hline S-N (mm) & 2.78 & 1.11 & 2.69 & 0.90 & -0.81 to 1.04 & 0.840 \\
\hline \multicolumn{7}{|c|}{ Maxillary Skeletal Component } \\
\hline $\operatorname{SNA}\left({ }^{\circ}\right)$ & 0.89 & 1.16 & -0.38 & 1.59 & 0.00 to 2.54 & $0.049^{*}$ \\
\hline $\mathrm{CoA}(\mathrm{mm})$ & 5.54 & 1.53 & 5.25 & 1.30 & -1.02 to 1.59 & 0.651 \\
\hline A-Nperp (mm) & 1.81 & 1.60 & 1.09 & 1.35 & -0.63 to 2.09 & 0.278 \\
\hline \multicolumn{7}{|c|}{ Mandibular Skeletal Component } \\
\hline $\operatorname{SNB}\left({ }^{\circ}\right)$ & 0.93 & 1.16 & -0.86 & 1.38 & 0.63 to 2.96 & $0.004^{*}$ \\
\hline Co-Gn (mm) & 7.53 & 1.02 & 5.57 & 0.83 & 1.08 to 2.80 & $0.001^{*}$ \\
\hline P-Nperp (mm) & 3.69 & 3.65 & 1.01 & 4.44 & -1.05 to 6.35 & 0.146 \\
\hline \multicolumn{7}{|c|}{ Maxillomandibular relationship } \\
\hline ANB $\left({ }^{\circ}\right)$ & 0.00 & 1.05 & 0.54 & 1.76 & -1.86 to 0.72 & 0.391 \\
\hline mx/md dif. (mm) & 1.65 & 1.44 & 0.54 & 1.91 & -0.42 to 2.65 & 0.146 \\
\hline \multicolumn{7}{|c|}{ Vertical Component } \\
\hline OP.FH $\left(^{\circ}\right)$ & -4.44 & 5.14 & -2.77 & 4.71 & -6.96 to 3.63 & 0.511 \\
\hline PP.FH $\left({ }^{\circ}\right)$ & -1.54 & 2.21 & -1.00 & 2.14 & -2.54 to 1.45 & 0.573 \\
\hline FMA $\left(^{\circ}\right)$ & -3.50 & 2.41 & -1.13 & 3.40 & -5.05 to 0.29 & 0.079 \\
\hline SNGoGn $\left({ }^{\circ}\right)$ & -2.05 & 1.64 & 1.22 & 1.90 & -4.90 to -1.65 & $<0.001^{*}$ \\
\hline UFH (mm) & 0.53 & 0.75 & 0.98 & 0.76 & -1.14 to 0.25 & 0.197 \\
\hline LAFH (mm) & 2.18 & 1.83 & 2.73 & 2.17 & -2.38 to 1.29 & 0.537 \\
\hline $\mathrm{PFH}(\mathrm{mm})$ & 4.28 & 2.51 & 2.40 & 1.37 & 1.04 to 5.32 & 0.050 \\
\hline Co-Go (mm) & 6.88 & 2.53 & 3.69 & 2.08 & -5.09 to 3.76 & $0.005^{*}$ \\
\hline \multicolumn{7}{|c|}{ Maxillary dentoalveolar component } \\
\hline Mx1.NA $\left({ }^{\circ}\right)$ & 3.40 & 6.23 & 2.35 & 7.01 & -5.00 to 7.11 & 0.718 \\
\hline $\mathrm{M} \times 1-\mathrm{NA}(\mathrm{mm})$ & -0.15 & 1.82 & 0.00 & 2.03 & -1.91 to 1.62 & 0.858 \\
\hline Mx1-PP (mm) & 0.49 & 1.55 & 0.99 & 1.81 & -2.04 to 1.04 & 0.504 \\
\hline Mx6.SN $\left({ }^{\circ}\right)$ & 4.90 & 6.04 & 2.41 & 3.78 & -2.79 to 7.77 & 0.329 \\
\hline $\mathrm{Mx6-PP}(\mathrm{mm})$ & 2.74 & 2.06 & 2.75 & 1.83 & -2.10 to 2.07 & 0.991 \\
\hline \multicolumn{7}{|c|}{ Mandibular dentoalveolar component } \\
\hline $\operatorname{Md} 1 . N B\left({ }^{\circ}\right)$ & 1.72 & 4.43 & 1.43 & 4.00 & -3.58 to 4.17 & 0.874 \\
\hline Md1-NB (mm) & 0.20 & 1.09 & 0.56 & 0.96 & -1.30 to 0.56 & 0.434 \\
\hline $\operatorname{IMPA}\left({ }^{\circ}\right)$ & 2.94 & 4.77 & 0.67 & 4.18 & -1.84 to 0.56 & 0.261 \\
\hline Md1-MP (mm) & 1.02 & 1.62 & 1.40 & 1.04 & -1.65 to 0.87 & 0.541 \\
\hline Md6.MP $\left({ }^{\circ}\right)$ & 0.77 & 8.87 & -3.37 & 7.23 & -3.75 to 12.04 & 0.283 \\
\hline Md6-MP (mm) & 1.05 & 1.33 & 0.74 & 1.63 & -1.14 to 1.72 & 0.657 \\
\hline \multicolumn{7}{|c|}{ Dental Relationship } \\
\hline Overjet (mm) & -0.65 & 0.83 & 0.20 & 0.90 & -1.82 to 0.09 & 0.072 \\
\hline Overbite (mm) & -0.43 & 0.89 & 0.09 & 1.49 & -1.94 to 0.84 & 0.427 \\
\hline $\operatorname{Mx1.Md1}\left({ }^{\circ}\right)$ & -4.84 & 8.74 & -2.30 & 10.12 & -11.16 to 6.07 & 0.543 \\
\hline \multicolumn{7}{|c|}{ Soft tissue } \\
\hline Nasolabial Angle $\left({ }^{\circ}\right)$ & -2.57 & 8.54 & -9.99 & 12.82 & -2.44 to 17.28 & 0.132 \\
\hline UL cant $\left({ }^{\circ}\right)$ & -3.76 & 6.60 & 3.16 & 8.63 & -13.90 to 0.05 & 0.517 \\
\hline UL-Eplane (mm) & -5.14 & 1.81 & -1.69 & 1.40 & -4.93 to -1.93 & $<0.001^{*}$ \\
\hline LL-Eplane (mm) & -3.19 & 1.73 & -1.43 & 0.92 & -3.01 to -0.45 & $0.010^{*}$ \\
\hline UL thickness (mm) & -3.04 & 1.62 & -1.94 & 1.66 & -2.58 to 0.43 & 0.143 \\
\hline LL thickness (mm) & 1.60 & 2.05 & 0.94 & 1.77 & -1.12 to 2.42 & 0.447 \\
\hline Chin thickness (mm) & 3.87 & 1.31 & 1.55 & 1.64 & 0.97 to 3.68 & $0.002^{*}$ \\
\hline Mx1 exposure $(\mathrm{mm})$ & -4.19 & 1.60 & -3.12 & 2.22 & -2.80 to 0.72 & 0.219 \\
\hline
\end{tabular}

*Statistically significant after applying Holm-Bonferroni correction ( $p$-values regarded stepwise from 0.006 to 0.05 ). 


\section{Influence of tooth losses}

The subgroup with tooth loss showed a greater increase of the posterior facial height $(4.25 \mathrm{~mm}$; $\mathrm{p}<0.035)$ and ramus height $(7.01 \mathrm{~mm} ; \mathrm{p}<0.001)$ compared to the group without multiple tooth loss (Table 4).

\section{Discussion}

To our knowledge, this is the first cephalometric study evaluating aging up to the seventh decade of life in normal occlusion subjects. Studies have evaluated

Table 4- Comparison between subgroups with and without tooth loss (t-tests)

\begin{tabular}{|c|c|c|c|c|c|c|}
\hline \multirow[t]{2}{*}{ Variables } & \multicolumn{2}{|c|}{ Without tooth loss $(n=9)$} & \multicolumn{2}{|c|}{ With tooth losses $(n=12)$} & \multirow[t]{2}{*}{$\mathrm{Cl} 95 \%$} & \multirow[t]{2}{*}{$p$} \\
\hline & Mean & SD & Mean & SD & & \\
\hline \multicolumn{7}{|c|}{ Cranial Base } \\
\hline $\mathrm{S}-\mathrm{N}(\mathrm{mm})$ & 2.56 & 0.98 & 2.88 & 1.03 & -1.25 to 0.61 & 0.480 \\
\hline \multicolumn{7}{|c|}{ Maxillary Skeletal Component } \\
\hline $\operatorname{SNA}\left({ }^{\circ}\right)$ & 0.52 & 1.02 & 0.10 & 1.79 & -0.99 to 1.81 & 0.544 \\
\hline $\mathrm{CoA}(\mathrm{mm})$ & 5.29 & 1.24 & 5.49 & 1.55 & -1.52 to -0.15 & 0.755 \\
\hline A-Nperp (mm) & 1.32 & 0.62 & 1.58 & 1.94 & -1.67 to 1.15 & 0.705 \\
\hline \multicolumn{7}{|c|}{ Mandibular Skeletal Component } \\
\hline $\operatorname{SNB}\left({ }^{\circ}\right)$ & -0.11 & 1.06 & 0.22 & 1.86 & -1.79 to 1.11 & 0.634 \\
\hline Co-Gn (mm) & 5.95 & 0.63 & 7.09 & 1.56 & -2.30 to 0.02 & 0.054 \\
\hline P-Nperp (mm) & 1.37 & 2.18 & 3.21 & 5.16 & -5.69 to 2.02 & 0.331 \\
\hline \multicolumn{7}{|c|}{ Maxillomandibular relationship } \\
\hline ANB $\left({ }^{\circ}\right)$ & 0.74 & 1.07 & -0.11 & 1.58 & -0.42 to 2.14 & 0.176 \\
\hline $\mathrm{mx} / \mathrm{md}$ dif. (mm) & 0.66 & 1.50 & 1.59 & 1.49 & -2.32 to 0.44 & 0.171 \\
\hline \multicolumn{7}{|c|}{ Vertical Component } \\
\hline OP.FH $\left({ }^{\circ}\right)$ & -2.47 & 4.22 & -5.92 & 5.14 & -1.56 to 8.46 & 0.162 \\
\hline PP.FH $\left(^{\circ}\right)$ & -0.73 & 1.44 & -1.70 & 2.52 & -1.00 to 2.94 & 0.318 \\
\hline FMA $\left(^{\circ}\right)$ & -1.41 & 1.39 & -3.10 & 3.83 & -1.13 to 4.50 & 0.225 \\
\hline SNGoGn $\left({ }^{\circ}\right)$ & 0.13 & 1.47 & -0.96 & 2.89 & -1.11 to 3.31 & 0.312 \\
\hline UFH (mm) & 0.64 & 0.78 & 0.82 & 0.78 & -0.90 to 0.54 & 0.609 \\
\hline LAFH (mm) & 2.10 & 0.78 & 2.69 & 2.54 & -2.43 to 1.26 & 0.513 \\
\hline $\mathrm{PFH}(\mathrm{mm})$ & 2.23 & 1.09 & 4.25 & 2.48 & -3.88 to -0.15 & $0.035^{*}$ \\
\hline Co-Go (mm) & 3.16 & 1.83 & 7.01 & 2.20 & -5.74 to -1.95 & $<0.001^{*}$ \\
\hline \multicolumn{7}{|c|}{ Maxillary dentoalveolar component } \\
\hline Mx1.NA $\left({ }^{\circ}\right)$ & 2.71 & 6.42 & 3.05 & 6.79 & -6.46 to 5.79 & 0.909 \\
\hline $\mathrm{M} \times 1-\mathrm{NA}(\mathrm{mm})$ & -0.74 & 1.26 & 0.42 & 2.15 & -2.85 to 0.52 & 0.166 \\
\hline $\mathrm{M} \times 1-\mathrm{PP}(\mathrm{mm})$ & 0.80 & 1.20 & 0.68 & 1.98 & -1.44 to 1.69 & 0.865 \\
\hline $\operatorname{Mx6.SN}\left({ }^{\circ}\right)$ & 4.43 & 5.27 & 2.30 & 4.42 & -3.19 to 7.46 & 0.405 \\
\hline Mx6-PP (mm) & 2.50 & 1.33 & 3.05 & 2.48 & -2.61 to 1.51 & 0.577 \\
\hline \multicolumn{7}{|c|}{ Mandibular dentoalveolar component } \\
\hline $\operatorname{Md1.NB}\left({ }^{\circ}\right)$ & 0.70 & 4.43 & 2.25 & 3.95 & -5.39 to 2.29 & 0.408 \\
\hline Md1-NB (mm) & 0.07 & 1.12 & 0.60 & 0.92 & -1.46 to 0.39 & 0.244 \\
\hline IMPA $\left({ }^{\circ}\right)$ & 1.42 & 4.29 & 5.06 & 5.37 & -8.21 to 0.92 & 0.111 \\
\hline Md1-MP (mm) & 1.09 & 0.97 & 1.28 & 1.62 & -1.47 to 1.08 & 0.757 \\
\hline $\operatorname{Md6.MP~}\left({ }^{\circ}\right)$ & -4.71 & 6.40 & 1.97 & 8.62 & -14.11 to 0.74 & 0.074 \\
\hline Md6-MP (mm) & 1.05 & 1.63 & 0.92 & 1.34 & -1.47 to 1.41 & 0.969 \\
\hline \multicolumn{7}{|c|}{ Dental Relationship } \\
\hline Overjet (mm) & 0.22 & 0.96 & -0.67 & 0.72 & -0.03 to 1.83 & 0.058 \\
\hline Overbite (mm) & -0.13 & 1.30 & -0.14 & 1.30 & -1.40 to 1.42 & 0.990 \\
\hline $\operatorname{Mx1} \cdot \operatorname{Md} 1\left(^{\circ}\right)$ & -0.83 & 6.43 & -5.73 & 10.73 & -3.56 to 13.36 & 0.240 \\
\hline \multicolumn{7}{|c|}{ Soft tissue } \\
\hline Nasolabial Angle $\left({ }^{\circ}\right)$ & -0.34 & 9.31 & -0.55 & 7.77 & -7.58 to 8.01 & 0.954 \\
\hline UL cant $\left({ }^{\circ}\right)$ & -3.76 & 6.60 & 3.16 & 8.63 & -14.83 to 5.09 & 0.517 \\
\hline UL-Eplane (mm) & -3.10 & 2.69 & -3.79 & 2.18 & -1.54 to 2.91 & 0.525 \\
\hline LL-Eplane (mm) & -2.45 & 1.56 & -2.28 & 1.75 & -1.72 to 1.37 & 0.815 \\
\hline UL thickness (mm) & -2.94 & 1.46 & -2.20 & 1.85 & -2.30 to 0.83 & 0.340 \\
\hline LL thickness (mm) & 0.65 & 1.54 & 1.76 & 2.08 & -2.83 to 0.62 & 0.195 \\
\hline Chin thickness $(\mathrm{mm})$ & 1.93 & 2.02 & 3.39 & 1.54 & -3.07 to 0.17 & 0.077 \\
\hline Mx1 exposure $(\mathrm{mm})$ & -3.45 & 2.20 & -3.85 & 1.82 & -1.43 to 2.24 & 0.649 \\
\hline
\end{tabular}

*Statistically significant after applying Holm-Bonferroni correction ( $p$ values regarded stepwise from 0.025 to 0.05 ). 
maturational changes of the craniofacial complex in untreated individuals. 1,2,8,10,14,15,20 One of the limitations of longitudinal studies is the difficulty in collecting data, which restricts the sample size. ${ }^{14,15,21,22}$ The difficulty in recalling the sample after 47 years were relevant considering the subjects had changed phone numbers and addresses. Additionally, women had adopted marital names. After trying to reach all the 82 subjects from the initial sample group, 24 were reached, of which 21 accepted to participate. A post-hoc power analysis showed a statistical power of $99 \%$, validating our results. Behrents' study from 1984 had only 4 subjects followed after 40 years of age. However, his results represented a very important contribution to clinical orthodontics on adult facial growth, and still are unique. Our study sample was selected from a historical sample of normal occlusion subjects collected in the late 60s. Therefore, a limited number of subjects were available for a second evaluation 40 years later. Despite the small sample, we achieved an adequate power, and the results showed several changes in skeletal and soft tissues with aging, confirming that craniofacial development continued into adulthood, as previously reported $^{1}$ (Figure 2). Soft tissues presented most significant changes compared to those of dentoskeletal tissues, agreeing with previous studies performed in untreated individuals. ${ }^{1,10,14,15}$

Considering the complete sample, cranial base length showed a significant increase over 44 years (Figure 2a, Table 2). This finding agrees with previous studies $^{14,23}$, and is associated to the anterior movement of frontal and nasal bones ${ }^{1,24}$, or in combination with posterior movement of the sella. ${ }^{24}$ Maxillary length and protrusion increased significantly. Mandibular length and protrusion also significantly increased from T1 to T2. These results corroborate previous longitudinal studies after adolescence showing that the maxilla and mandible continue to grow during adulthood. 2,10,14,15,23,25 Bone apposition on the anterior surface of the symphysis might also have occurred, contributing to the anterior mandibular displacement. ${ }^{23}$

In general, the upper facial height increase might be associated with the downward movement of the anterior nasal spine. The lower anterior facial height increase was greater than the upper facial height increase, and probably subsequent to teeth eruption. ${ }^{1,14}$ The ramus height increase explains most of the posterior facial height increase ${ }^{1}$ (Figure 2a). Our vertical skeletal findings corroborate previous studies on maturational changes in untreated subjects. ${ }^{1,10,14,15}$

Dentoalveolar changes included significant mesial angulation of the maxillary molars. Increase of the maxillary molar angulation can be explained by a mesial shift of posterior teeth throughout life $\mathrm{e}^{1,26,27}$, and mesiodistal tooth size reduction during aging. ${ }^{21}$ Significant vertical development of the maxillary and mandibular first molars and mandibular incisors were also observed, confirming that teeth continue to erupt over time during adulthood.5,15 A study by West and McNamara $^{15}$ (1999), with subjects from 17 to 47 years of age, showed vertical developments of $1.1 \mathrm{~mm}$, $1.8 \mathrm{~mm}$ and $1.6 \mathrm{~mm}$ for maxillary and mandibular first molars and mandibular incisors, respectively. A previous 40-year follow up of subjects with normal occlusion using digital dental models showed increases of clinical crown height, slight incisor crowding, decrease of mesiodistal tooth size, decrease of the mandibular intercanine width and arch perimeter, and, finally, slight overbite reduction during aging. ${ }^{21}$ These changes should be considered during orthodontic treatment planning in adult patients.

Over 40 years, changes to the facial soft tissue were quantitatively more expressive than dentoskeletal changes (Table 2). The nasolabial angle decreased $6.1^{\circ}$ despite the retrusion, and decreased thickness of the upper lip, indicating that downward movement of the nasal columella occurred during aging (Figure 2a). A previous study measured the vertical development of the columella relative to the Frankfurt plane, showing an increase of $3.8 \mathrm{~mm}$ from 17 to 57 years of age, which confirms a nasal downward movement over time. ${ }^{14}$ Other studies also reported similar findings of downward movement of the nose with ageing. ${ }^{1,10,15,20,28}$ Lips became more retruded, specially the upper lip. Considering the inexistence of significant changes for maxillary and mandibular incisor protrusion with aging, lip retrusion is probably mostly related to forward movement of the nose and chin, and to an actual decrease of upper lip thickness. Similar findings were reported in previous studies in untreated subjects. ${ }^{1,10,14}$ Reduction of upper lip thickness observed in our study might be related to the natural aging process of the skin which becomes less consistent and inelastic over time. ${ }^{1,10,14,29}$ In contrast to the upper lip, the lower lip showed a slight thickness increase of $1.28 \mathrm{~mm}$. Behrents $^{1}$ (1984) also found more prominent lower lip during aging, contributing to a deepening of the mentolabial sulcus. Soft chin thickness also increased, 
corroborating previous studies. ${ }^{1,14}$ A study in normal occlusion subjects between 20 and 30 years of age showed that lower lip and soft chin thickness increased a mean of $0.55 \mathrm{~mm}$ and $0.51 \mathrm{~mm}$, respectively. ${ }^{30}$ Both the nose and soft chin changes should increase the perception of bi-retruded lips with aging. Additionally, maxillary incisor exposure decreased, probably due to the upper lip vertical changes added to the natural force of gravity and to the occurrence of an incisal edge wear in the central incisors. ${ }^{21}$ The $3.68 \mathrm{~mm}$ reduction in maxillary incisor exposure over a 40-year follow-up indicates a rate of approximately $1 \mathrm{~mm}$ loss of maxillary incisor display every decade. A previous study in Korean subjects between 20 and 69 years of age showed a gradual decrease in maxillary incisor exposure of $4 \mathrm{~mm}$, and a $3 \mathrm{~mm}$ increase in mandibular tooth exposure in the rest position. ${ }^{31}$ Other studies found similar changes. ${ }^{32-34}$

Craniofacial changes over the 40-year period presented sexual differences (Figure 2b, c; Table 3). Males presented maxillary and mandibular protrusion, and counterclockwise rotation of the mandible (Figure 2b). In contrast, females showed slight maxillary and mandibular retrusion, and clockwise rotation of the mandible (Figure $2 \mathrm{c}$ ). Our results agree with previous studies in untreated subjects. ${ }^{1,14,15}$ Pecora, et al. ${ }^{14}$ (2008) also showed sexual mandibular growth differences in subjects between 17 and 47 years, among which women showed more vertical changes and posterior rotation of the mandible, whereas men showed a more anterior mandibular rotation. Both sexes showed increase in the mandibular ramus height (Co-Go) from T1 to T2; however, men showed a significantly greater increase than women which corroborate other studies.1,2,15 The greater increase in ramus height in men could be associated with the counterclockwise rotation of the mandible. ${ }^{1}$ Furthermore, several men had not completed their circumpubertal active growth at T1 considering the wide age range. Considering the cervical vertebral maturation, ${ }^{35}$ seven out of 11 male subjects were at CS5 and three were still at CS4 at 17 years of age. On the contrary, six out of 10 female subjects showed stage CS6 at T1. These differences in sexual skeletal maturation at T1 could explain the greater changes observed in men between 17 and 61 years of age. The sexual differences in soft tissue changes consisted in greater retrusion of the upper and lower lips in males that might be related to the greater increase of nose and soft chin dimensions. These findings corroborate previous studies. ${ }^{1,2,15,36}$ Soft chin thickness increased more in males than in females in a $3: 1$ ratio (Figure $2 b$ and $\mathrm{c}$ ). These results support previous studies showing similar findings. ${ }^{1,14,29,33}$

The subgroup with tooth loss showed greater increase of the posterior facial height and ramus height than the subgroup without multiple tooth loss (Table $4)$. These results might be due to a counterclockwise rotation of the mandibular plane that occurs in subjects with posterior tooth losses, decreasing the vertical occlusal dimension. Our findings corroborate a previous study that compared mandibular size of edentulous, old dentate and young dentate individuals and showed significant greater ramus length in edentulous individuals, compared to young and old dentate individuals. ${ }^{37}$ Hutchinson, Farella and Kramer (2015) found edentulous mandible with greater ramus height compared to dentate and partially edentulous mandibles. Differences between subgroups should be interpreted with caution due to the reduced sample power - a limitation of our study. Despite this limitation, this is the first cephalometric study following subjects with untreated normal occlusion until 70 years of age.

In short, this study has provided further evidence that the craniofacial complex continues to change from early to mature adulthood, probably due to terminal growth and bone remodeling processes throughout life. ${ }^{1}$ Several changes in the dentoskeletal and soft tissues might be expected with aging in subjects with normal occlusion. As clinical considerations, orthodontists should be very careful when suggesting procedures that reduce lip protrusion, straighten the facial profile, and decrease maxillary incisor display, to avoid accelerating facial aging.

\section{Conclusions}

Between 17 and 61 years of age, normal occlusion subjects present anterior displacement of the maxilla and mandible, and increases in facial heights; maxillary molars showed mesial angulation and extrusion. The mandibular incisors and molars also extruded with aging. They also showed closure of the nasolabial angle, retrusion of the lips, increase of the soft-tissue chin, and reduction of the maxillary incisor exposure occurred during aging. These subjects also showed sexual differences in the craniofacial changes from 
early to mature adulthood. Finally, subjects with multiple tooth losses presented a greater increase in mandibular ramus height.

\section{Ackowledgment}

This study was financed in part by the Coordination of Higher Education and Graduate Training - Brazil (CAPES) - Finance Code 001 and by the São Paulo Research Foundation (FAPESP - grants \#2017/112159). We would like to thank all orthodontists of Bauru Dental School who collected the sample in the 60s and 70s.

\section{Conflict of interest}

The authors declare no conflicts of interest.

\section{Authors' contributions}

Garib, Daniela Gamba: Conceptualization (Equal); Methodology (Equal); Project administration (Equal); Supervision (Equal); Writing-original draft (Equal). Natsumeda, Gabriela Manami: Data curation (Equal); Formal analysis (Equal); Funding acquisition (Equal); Investigation (Equal); Methodology (Equal); Original draft (Equal). Massaro, Camila: Data curation (Equal); Supervision (Equal). Miranda, Felicia: Data curation (Equal); Supervision (Equal). Naveda, Rodrigo: Methodology (Equal). Janson, Guilherme: Supervision (Equal); Writing-original draft (Equal).

\section{References}

1- Behrents RG. A treatise on the continuum of growth in the aging craniofacial skeleton [thesis]. University of Michigan, Ann Arbor 1984. v.I and II.

2- Bishara SE, Treder JE, Jakobsen JR. Facial and dental changes in adulthood. Am J Orthod Dentofacial Orthop. 1994;106(2):175-86. doi 10.1016/S0889-5406(94)70036-2

3- Broadbent B Jr, Golden WH, Brown RG. Bolton standards of dentofacial development growth. Plast Reconstr Surg. 1977;59(1):115 4- Riolo ML, Moters RE, McNamara JA Jr, Hunter, WS. An atlas of craniofacial growth: cephalometric standards from the University School Growth Study, the University of Michigan. Ann Arbor, MI: Center for Human Growth and Development, University of Michigan; 1974. 5- Sinclair PM, Little RM. Dentofacial maturation of untreated normals. Am J Orthod. 1985;88(2):146-56. doi: 10.1016/0002-9416(85)902398

6- Stahl de Castrillon F, Baccetti T, Franchi L, Grabowski R, Klink Heckmann U, McNamara JA. Lateral cephalometric standards of Germans with normal occlusion from 6 to 17 years of age. J Orofac Orthop. 2013;74(3):236-56. doi: 10.1007/s00056-013-0140-5

7- Andrews LF. The six keys to normal occlusion. Am J Orthod. 1972;62(3):296-309. doi: 10.1016/s0002-9416(72)90268-0
8- Bishara SE. Facial and dental changes in adolescents and their clinical implications. Angle Orthod. 2000;70(6):471-83. doi: 10.1043/0003-3219(2000)070<0471:FADCIA>2.0.CO;2

9- Bjork A. Variations in the growth pattern of the human mandible: longitudinal radiographic study by the implant method. J Dent Res. 1963;42(1)Pt 2:400-11. doi: 10.1177/00220345630420014701 10- Formby WA, Nanda RS, Currier GF. Longitudinal changes in the adult facial profile. Am J Orthod Dentofacial Orthop. 1994;105(5):464-76. doi: 10.1016/S0889-5406(94)70007-9

11- Forsberg CM, Odenrick L. Changes in the relationship between the lips and the aesthetic line from eight years of age to adulthood. Eur J Orthod. 1979;1(4):265-70. doi: 10.1093/ejo/1.4.265

12- Israel $\mathrm{H}$. Age factor and the pattern of change in craniofacial structures. Am J Phys Anthropol. 1973;39(1):111-28. doi: 10.1002/ ajpa.1330390112

13- Kendrick GS, Risinger HL. Changes in the anteroposterior dimensions of the human male skull during the third and fourth decade of life. Anat Rec. 1967;159(1):77-81. doi: 10.1002/ar.1091590111 14- Pecora NG, Baccetti T, McNamara JA Jr. The aging craniofacial complex: a longitudinal cephalometric study from late adolescence to late adulthood. Am J Orthod Dentofacial Orthop. 2008;134(4):496-505. doi: 10.1016/j.ajodo.2006.11.022

15- West KS, McNamara JA, Jr. Changes in the craniofacial complex from adolescence to midadulthood: a cephalometric study. Am J Orthod Dentofacial Orthop. 1999;115(5):521-32. doi: 10.1016/s08895406(99)70274-x

16- Dupont WD, Plummer WD Jr. Power and sample size calculations. A review and computer program. Control Clin Trials. 1990;11(2):11628. doi: 10.1016/0197-2456(90)90005-m doi: 10.1016/01972456(90)90005-m

17- Lang NP, Adler R, Joss A, Nyman S. Absence of bleeding on probing. An indicator of periodontal stability. J Clin Periodontol. 1990;17(10):714-21. doi: 10.1111/j.1600-051x.1990.tb01059.x 18- Dahlberg G. Statistical methods for medical and biological students. New York: Interscience Publications; 1940.

19- Perinetti G. StaTips Part V: The adjustment of the P value in the context of multiple comparisons. South Eur J Orthod Dentofac Res. $2018 ; 5(2): 20-2$

20- Forsberg CM. Facial morphology and ageing: a longitudinal cephalometric investigation of young adults. Eur J Orthod. 1979;1(1):15-23. doi: 10.1093/ejo/1.1.15

21- Massaro C, Miranda F, Janson G, Almeida RR, Pinzan A, Martins $D R$, et al. Maturational changes of the normal occlusion: a 40-year follow-up. Am J Orthod Dentofacial Orthop. 2018;154(2):188-200. doi: 10.1016/j.ajodo.2017.10.028

22- Miranda F, Massaro C, Janson G, Freitas MR, Henriques JF, Lauris $J R$, et al. Aging of the normal occlusion. Eur J Orthod. 2018;41(2):196203. doi: $10.1093 /$ ejo/cjy044

23- Behrents RG. Growth in the aging craniofacial skeleton. Ann Arbor: Center for Human Growth and Development, University of Michigan; 1985.

24- Sarnäs KV, Solow B. Early adult changes in the skeletal and softtissue profile. Eur J Orthod. 1980;2(1):1-12.

25- Bjork A, Skieller V. Growth of the maxilla in three dimensions as revealed radiographically by the implant method. $\mathrm{Br} \mathrm{J}$ Orthod. 1977;4(2):53-64. doi: 10.1179/bjo.4.2.53

26- Bishara SE, Treder JE, Damon P, Olsen M. Changes in the denta arches and dentition between 25 and 45 years of age. Angle Orthod. 1996;66(6):417-22. doi: 10.1043/0003-3219(1996)066<0417:CIT $\mathrm{DAA}>2.3 . \mathrm{CO} ; 2$

27- Tibana RH, Palagi LM, Miguel JA. Changes in denta arch measurements of young adults with normal occlusion: a longitudinal study. Angle Orthod. 2004;74(5):618-23. doi: 10.1043/0003-3219(2004)074<0618:CIDAMO>2.0.CO;2 
28- Subtelny J. A longitudinal study of soft tissue facial structures and their profile characteristics, defined in relation to underlying skeletal structures. Am J Orthod Dentofacial Orthop. 1959;45(7):481-507.

29- Nanda RS, Meng H, Kapila S, Goorhuis J. Growth changes in the soft tissue facial profile. Angle Orthod. 1990;60(3):177-90.

30- Tibana RH, Palagi LM, Carneiro MS, Almeida MA, Miguel JA. Changes in facial profile of young adults with normal occlusion: a longitudinal study. World J Orthod. 2008;9(2):114-120.

31- Choi T, Jin T, Dong J. A study on the exposure of maxillary and mandibular central incisor in smiling and physiological rest position. J Dental Res. $1995 ; 74(3): 1000$.

32- Dong JK, Jin TH, Cho HW, Oh SC. The esthetics of the smile: a review of some recent studies. Int J Prosthodont. 1999;12(1):9-19.

33- Vahdettin L, Altug Z. Longitudinal soft-tissue profile changes in adolescent Class I subjects. J Orofac Orthop. 2012;73(6):440-53. doi: 10.1007/s00056-012-0099-7

34- Van der Geld P, Oosterveld P, Kuijpers-Jagtman AM. Age-related changes of the dental aesthetic zone at rest and during spontaneous smiling and speech. Eur J Orthod. 2008;30(4):366-73. doi: 10.1093/ ejo/cjno09
35- Baccetti T, Franchi L, McNamara JA, Jr. An improved version of the cervical vertebral maturation (CVM) method for the assessment of mandibular growth. Angle Orthod. 2002;72(4):316-23. doi: 10.1043/0003-3219(2002)072<0316:AIVOTC>2.0.CO;2

36- Zylinski CG, Nanda RS, Kapila S. Analysis of soft tissue facial profile in white males. Am J Orthod Dentofacial Orthop. 1992;101(6):514-8. doi: 10.1016/0889-5406(92)70125-T

37- Sairam V, Potturi GR, Praveen B, Vikas G. Assessment of effect of age, gender, and dentoalveolar changes on mandibular morphology: a digital panoramic study. Contemp Clin Dent. 2018;9(1):49-54. doi: 10.4103/ccd.ccd_704_17

38- Hutchinson EF, Farella M, Kramer B. Importance of teeth in maintaining the morphology of the adult mandible in humans. Eur J Oral Sci. 2015;123(5):341-9. doi: 10.1111/eos.12203 